\title{
5 \\ Customer Control of IN Services
}

\author{
O. Fargemand, A. Jensen
}

Tele Danmark

$R \& D$ Telephony Services

Telegade 2, DK-2630 Tåstrup, Denmark

tel: +4543344334

fax: +4543718864

e-mail: of@tdk.dk,alljn@tdk.dk

\begin{abstract}
Customer control is becoming an important part of IN-services. Customer control allows the customer to control the setting of his service profile and other data associated with his services. The paper categorises IN-customer into three categories: residential, Small Office and Home Office and business, and discusses their needs for customer control. The paper discusses different ways of implementing customer control: IVR, WWW, proprietary tools and direct access solutions. The paper presents some recent implementations of customer control at Tele Danmark. Finally some future possibilities for customer control are presented.
\end{abstract}

Keywords

Customer control, IN-service, IVR, DTMF, WWW, VPN.

Intelligent Networks and Intelligence in Networks D. Gaiti (Ed.)

Published by Chapman \& Hall 다이 1997 IFIP 


\section{INTRODUCTION}

In this paper we use "Customer Control" as the ability of the user to control the set-up of his services. Telecommunication services can be implemented in the telecommunications network in various ways. Implementation by IN (Intelligent Network) allows fast and flexible service provisioning. Because speed and flexibility in service offering is a main driver for the use of IN services, customer control of IN services is becoming an important topic for service operators.

Customer control is a subset of Service Management. Strictly defined it excludes the handling of services by the service operator staff. The service operator staff must off course be able to provide the part of service management included in customer control on behalf of the customers - when required.

Customer control includes controlled changes to the service data, i.e. the database of the IN, whereas it does not - for the time being - include changes to the service logic itself. This distinction is not strict and may depend on the type of INplatform being used, but it focuses our present concerns about offering customer control.

Customer control is seen as beneficial by the service operator for at least two reasons:

- Do-it-yourself by the customer frees operational staff at the service operator from setting up service data for the customer.

- Customer control lets the customer experience more control of his services and more flexible service maintenance, thereby increasing the customer satisfaction.

In the following we characterise the various segments of IN service customers, the various technologies available for their customer control and the resulting possibilities.

\section{ACTORS IN CUSTOMER CONTROL AND THEIR NEEDS}

\subsection{Customer segments}

The customers of IN services can be categorised like the customers of telecommunication services in general. In practice, this categorisation is useful: 
- Residential customers

- Small Office and Home Office customers

- Business customers.

Residential customers mainly use IN-services like premium rate calling as service users and call diversion schemes as service customers. For customer control of premium rate calling they may want to change the access rights from their telephone and for call diversion they may want to change the routing scheme. The need for customer control is therefore mainly in the area of setting parameters (e.g. time and day and c-number) for call diversion. Attractive pricing and a simple user interface are important for the residential customer. The possibility of assistance from an operator (operator fall-back) is also important.

Small Office and Home Office (SOHO) customers are mainly using the same INservices as residential customers and some of the cheaper services for business customers (e.g. freephone within a restricted geographical area). Attractive pricing and a simple user interface are important parameters for the SOHO customer as well, but quality parameters such as reliability and availability of the service are becoming important.

Business customers are mainly using national services (e.g. freephone and a universal number for all branches) and international services (e.g. international freephone and VPN - Virtual Private Network). The quality of the service becomes crucial, because many people will depend on the service for the efficiency of their work. Availability of qualified on-line help from experts of the service operator is also important.

Customer control must be accompanied by the ability of the customer to verify his complete "service profile" with the service operator. This implies that efficient feedback must be given on any changes performed by customer control.

\subsection{Technologies available}

Interactive Voice Response (IVR) The push button telephone (DTMF - Dual Tone Multi Frequency) can be used for setting up IN-services as it is also done for subscriber services implemented in local switches by stimulus procedures (combinations of $*$, \# and figures). This interface is anticipated by vendors by offering IVR systems, intelligent peripherals (IP) to build voice-response systems as parts of the IN-platforms. The penetration of push button telephones is almost $100 \%$ in the Danish network and in practice it is assumed that any customer has access to at least one push button telephone. 
The lack of a display on ordinary (fixed network) telephones poses some limitations to the use of DTMF for Customer Control, and the penetration of display telephones (fixed network) is still very low. Even when ISDN-access (Integrated Services Digital Network) is well accepted by the customers, it is mainly used for PC's (Personal Computer) in connection with Internet access and not for ISDN-telephones with display.

The advantage of IVR for customer control is that the authenticity of the calling terminal can be assumed from the originating number and that DTMF can be assumed to be available to all our residential customers. The drawback is the complexity of entering large amounts of data via a telephone keypad without a display possibility. The user interface can somehow be improved e.g. by means of Speech Technology (see "Push Self Guide" below) but has its limitations, because it was not built for entering series of data, and because of the lack of a display.

Internet The penetration of WWW-technology (World Wide Web) and the availability of tools for building interactive homepages makes the Internet a very interesting user interface for customer control. It is appealing for services with customer control of bigger complexity than what can be handled by IVR. The security problems are bigger than for IVR, because Internet transmission in principle is unsecured and because the authenticity of the user cannot be assumed by the usage of a fixed, dedicated connection.

Proprietary vendor solutions Until recently all servicing of IN-services by network operator staff was done via a proprietary interface supplied by the INvendor. It allows to design form-based interfaces for entering data to IN-services. The design of the form as a service specific maintenance tool is part of the INservice design. This interface resembles the Internet-interface but because it is part of the IN-platform and operated by IN-platform staff, there are no special security problems. For customer control this interface is so far used on an off-line basis. Today network operator staff receives data from the customer and check the data before they are loaded on the network. The kind of customer controls which are handled this way resembles those which can be handled via Internet. This interface is used for customer control by utilising that each form defines a file format for entering data. This is utilised to format files of customer control data on e.g. a PC, and then load these data on the IN-network.

Direct access The optimal customer control for complex service data is a direct link between the customers' IT-system and the database of the IN-system. This link can today be set-up in different ways, e.g. by using FTP (File Transfer Protocol), RPC (Remote Procedure Call) or ODBC (Open DataBase Connectivity). Emerging technology in this area is covered later in the paper. 


\subsection{Resulting Possibilities}

With the available technology, the needs of the customers can be met in the following ways for various types of service data (simple, complex):

IVR is appealing for services with relatively simple customer control targeted at residential customers. IVR may both be used from a customers own telephone or from another telephone, in which case an authenticaion procedure including the use of a PIN (Personal Identification Number) is used.

WWW is required for more complex services and mainly for the business segment, where Internet access can be assumed. The main benefit of using the WWW is that the user interface is widely known, it allows the customer to connect from different machines and the tools for building specific user interfaces are easy to use.

Proprietary solutions cover the same area as WWW does. The advantages of the proprietary solutions are currently a better security, but as WWW eventually will include more secure access (such as those developed for electronic commerce and banking) the wider availability of tools for WWW will probably decrease the role of the proprietary solutions.

Direct access solutions to IN-databases will eventually be a demand from business customers in order to allow a smooth integration of their IN-services into other aspects of their organisation. These solutions must be seen together with the service operator's attempts to offer maximum control to the customers own services and network (Customer Premises Management).

\section{RECENT WORK AT TELE DANMARK}

\subsection{Remotely controlled call forwarding}

Call forwarding is implemented in the local switches in the Danish network. Changing the call forwarding from another telephone than the one being diverted is not available from the switch vendors. Therefore an IN-service has been developed which allows remotely changing the call forwarding. The IN-service prompts for the telephone number involved and the PIN used for authentication of the caller. After validating these data on the IN-platform a series of commands (MML, Man Machine Language) are sent via the management system to the switch involved and the call forwarding is changed. 
IVR is used for this customer control because the data entry is a telephone number and a PIN. The customers are used to supply this information via push buttons. The data may in principle be tapped on the network access, but the risk is comparable to other kind of data transmissions done via the telephone network.

\subsection{Do-it-yourself Guide}

A fully automated Help Desk, a 'Do-it-yourself Guide', has been developed for assisting the residential subscribers in the use of supplementary PSTN-services (Public Service Telephone Network). A problem in using supplementary services has been the user interface, where the customer controls the service by stimulus procedures. Instead the user is guided through a dialogue for setting up the services, eliminating the need for the user to remember service codes and formats for controlling the services. In addition, the help desk allows the customer to activate commands by speech. The system is connected to the O\&M-systems of the network and is able to support customer control of services which are implemented on IN or in the local switches. So far, the only IN-service utilising the system is the remotely controlled call forwarding.

\subsection{Virtual Private Network (VPN)}

VPN is a typical IN-service targeted at big business customers. Ideally the customer, who has subscribed to a VPN by this service have to define the subscribers belonging to the network and the private numbering plan used with the network. Maintaining this service profile is beyond what is feasible by means of IVR. For the time being, the preferred solution is to receive data from the customer via a PC, and check the data before they are entered via the proprietary interface of the IN platform.

\subsection{Televoting}

Televoting is a service that makes it possible for e.g. broadcasting companies to initiate a vote when and where they please. The customer can define when the voting is to take place, and whether only selected users can participate (based on the participants phone number). It is also possible to put a selected call through to the studio. It is an IN-service whose customer control addresses business users. Customer data is at the moment received via IVR, but a later version with more features will use a WWW interface. 


\section{ISSUES IN CUSTOMER CONTROL}

\subsection{Access control}

Access to customer control must be implemented in a way which ensures that the data belonging to one customer cannot be inspected or modified by another customer. Because the vendors' proprietary maintenance tool has been designed for operator use, it cannot be offered directly to the customers. In IVR-based customer control privacy can be achieved based on calling line identificaiton which is available throughout the Danish network. In cases where IVR is used from other telephones than the one of the customer, an identification procedure can be used. A central PIN server has been established in connection with our INplatform.

\subsection{Security}

Customer control must be implemented in a way which secures the communication between the customer and the operator. Tapping of DTMF signalling is possible by intruding into the customer installation, but DTMF is usually not stored on nonsecured machines outside the network operator premises. DTMF is sufficiently secure for customer control, as it is already assumed sufficiently secure for callset-up. Internet solutions usually lack the desired security, but with software appearing for e.g. electronic banking in connection with certification centres, WWW interfaces can be built, which will be superior to DTMF in terms of security.

\subsection{Validation of data}

When data are no longer entered via the service operator staff there is obviously a big need for validation before the data are allowed into the IN-platform. The service operator will be held responsible if a customer manages to tamper with his service profiles by unintended customer control. Some work is therefore needed in order to perform validation of customer data, keep a log of subscriber commands and to maintain a help desk which - even pro-actively - can assist customers who experience problems with customer control.

\section{FUTURE POSSIBILITIES}

\subsection{Direct Database Access}

Eventually customer control must be seen as the customers ability to access and update a private view of the IN-database associated with the customers services. Emerging technologies for open distributed databases will allow the customer to 
host and maintain the part of the IN-database associated with the customers services, in a safe way. Initiatives like ODP (Open Distributed Processing) and CORBA (Common Object Request Broker Architecture of the Obj. Mgt. Group consortium) are paving the way for this future.

\subsection{Agent Based customer control}

Agent technology is a broad term covering intelligent information retrieval and handling across a network. Agent technology could be important when designing more advanced control mechanisms for the customer. One could think of:

- conditional control: a certain parameter shall only be set, if another one has been defined or set to a certain value

- loops: certain parameters should be set for a number of parameters

- transforming high level goals into series of how and when. E.g. "One hour department meeting" into diversion of a number of telephones in one hour. .

Obviously there are a lot of possibilities in this technology and it may gradually lead us in the direction of customer design.

\subsection{Towards customer design}

The overall goal of a service operator is not to develop advanced services for the customers, but rather to offer an advanced service platform, which meets the customers needs for advanced services. Eventually technology in the shape of some safe, high-level service description language ("IN-Java") will allow for this. Services written in such a language could then be given a better performance by being ported to a more efficient traditional platform. A first step to this could be logic for combining service elements and their profiles (e.g. using agent technology).

There will still be a need for a service operator to develop more advanced services and service elements, but a number of services can be developed/composed by the customers themselves. Service operators may then be measured by the richness of their service element library and flexibility in service composition and customer control..

\section{ACKNOWLEDGEMENTS}

The authors acknowledge the valuable assistance from their colleagues Bent Banke, Finn Svejstrup, Henrik Thymann and Astrid Wilcken in finalising this paper. 


\section{REFERENCES}

Ericsson (1996) TMOS User Guide, Generic Service Adapter SCP/SDP Ericsson (1994) TMOS Operators Manual, SMAS 2.1 User Manual

\section{BIOGRAPHY}

Ove Færgemand graduated from the Technical University of Denmark 1975. Teaching at the University until 1983. 1983-92 head of group on "Software Techniques" at the Danish Telecom. Research Laboratory. 1992-95, project supervisor at the European Telecom Research Institute (EURESCOM) in Heidelberg. 1988-92 rapporteur in ITU-T SG 10, 1992-96 chairman of the SG. Currently head of the section Telephony Services at Tele Danmark R\&D. The work of section includes development of IN-services and speech technology. Publications include papers and books about SDL (ITU-T Specification and Description Language).

Allan Jensen, graduated from the Technical University of Denmark 1985. 1985-95 at the Danish Telecom. Research Laboratory managing the participation of the lab to a number of EU and EURESCOM projects related to Openness and Objectorientation in Telecommunications Systems architechtures. Currently developing IN-services in Tele Danmark R\&D Telephony Services. 